\title{
Cerebellar Development and Plasticity: Perspectives for Motor Coordination Strategies, for Motor Skills, and for Therapy
}

\author{
J.D. Swinny, ${ }^{1}$ J.J.L. van der Want ${ }^{2}$ and A. Gramsbergen ${ }^{3}$ \\ 'Laboratory for Stress Neurobiology, 409 Abramson Research Center, The Children's Hospital of \\ Philadelphia, Philadelphia, PA,19104, USA; ${ }^{2}$ Laboratory for Cell Biology and Electron Microscopy \\ and ${ }^{3}$ Medical Physiology, University Medical Center Groningen, The Netherlands
}

\begin{abstract}
The role of the mammalian cerebellum ranges from motor coordination, sensory-motor integration, motor learning, and timing to nonmotor functions such as cognition. In terms of motor function, the development of the cerebellum is of particular interest because animal studies show that the development of the cerebellar cortical circuitry closely parallels motor coordination. Ultrastructural analysis of the morphological development of the cerebellar circuitry, coupled with the temporal and spatial identification of the neurochemical substrates expressed during development, will help to elucidate their roles in the establishment of the cerebellar circuitry and hence motor activity. Furthermore, the convenience of a number of naturally occurring mouse mutations has allowed a functional dissection of the various cellular elements that make up the cerebellar circuitry. This understanding will also help in the approach to possible therapies of pathologies arising during development because the cerebellum is especially prone to such perturbation because of its late development.
\end{abstract}

Reprint requests to: J.D. Swinny, Lab for Stress Neurobiology, 409 Abramson Research Center, The Children's Hospital of Philadelphia, Philadelphia, PA 19104-4399, USA

\section{INTRODUCTION}

The role of the cerebellum is thought to be that of a coordinating center, using sensory inputs from the periphery to fine-tune movement and postural control (Doyon et al., 2002). Apart from motor coordination, the cerebellum is also thought to be involved in motor learning and higher cognitive function (Allen et al., 1997; Bloedel \& Bracha, 1997). The cerebellum, in relation to other brain structures, enjoys a protracted developmental profile, providing a convenient vantage point to view ongoing developmental processes.

Animal studies have shown that the development of the cerebellar cortical circuitry closely parallels motor development. Indeed, in terms of the rat, from the second postnatal week onward, the principal cell-type in the cerebellar cortex, the Purkinje neuron, embarks on an extensive process of synaptogenesis with its afferents and interneurons, including multiple climbing fibers synapsing on its cell body and parallel fibers synapsing on distal dendritic spines (Altman \& Bayer, 1997).

About this time, about postnatal days (PD) 89 , the rat is able to stand on all fours and is capable of inelegant, uncoordinated movements (Geisler et al., 1996). At the beginning of the third postnatal week (acutely between PD 15-16), the rat is able to stand on its hindlegs and move in a coordinated fashion (Westerga et al., 1999). This period corresponds to the formation of the monoinnervation between climbing fibers and Purkinje cell dendritic spines. Because of its protracted 
developmental profile, the cerebellar cortex in mammals provides an accessible model to study ongoing developmental events. Of immense benefit has been the number of naturally occurring mutations in the mouse cerebellum. The use of such mutants has elucidated the cellular and behavioral consequences of the lack of or the deletion of certain elements of the cerebellar circuitry. The establishment of causal relationships between neurochemical agents and well-defined behavioral patterns will help, firstly to cement our understanding of the factors involved in the development of the cerebellum and motor behavior and, importantly, will provide for more directed interventions in cases of pathology.

This review focuses on, firstly, certain mutant mice models that have been used to assess the effects of cerebellar malformation or degeneration and some of the trophic agents impacting upon the developing cerebellar cortex and the potential consequences thereof on motor behavior.

\section{DEVELOPMENT OF CEREBELLAR CIRCUITRY}

Compared with other brain structures, the cerebellum undergoes a protracted developmental profile, resulting in a large component of development occurring postnatally. In humans, the development of the cerebellum (and particularly the proliferation of future granule cells) starts in the last trimester of pregnancy and continues into the first year of life (Dobbing \& Sands, 1973). In rodents, the cerebellar cortex almost totally develops during the first 3 postnatal weeks (Altman \& Bayer, 1997).

The cells in the cerebellum arise from two different germinal matrices, namely the ventricular epithelium and the rhombic lip (see Goldowitz \& Hamre, 1998 for review). Deep cerebellar nuclei, Purkinje cells, Golgi, stellate, and basket cells all arise from the ventricular neuroepithelium. In the rat, the first cells to leave the ventricular zone are the deep cerebellar nuclei and vestibular nuclei at approximately embryonic day (E) 10-12. Around
E13, precursor Purkinje cells are born. Shortly after their final mitosis, they migrate during E14E17 along radial glial fibers over the already formed deep cerebellar nuclei into the cerebellar Anlage.

Also at this stage, Purkinje cells begin to express the calcium binding protein, calbindin. The formation of a secondary germinal matrix from the rhombic lip-the external granular layer (EGL)-occurs at about the time when nuclear and Purkinje cells have stopped dividing. As the EGL cells migrate over the cerebellar surface in a subpial position, the Golgi neurons are born from the diminishing ventricular zone. Postnatally, in rats, the EGL will seed the internal granular layer with an abundance of granule cells. Also generated at this time are the stellate and basket cells that colonize the molecular layer.

During the first postnatal week, Purkinje cells rearrange from a disordered multi-tiered layer to their characteristic monolayer, with their apical regions oriented towards the pial surface. Also at this stage, swellings in their apical regions of their somata, the apical caps, become pronounced. The apical caps are the regions from which the primary dendrites grow out. The two major afferent systems, namely the climbing fibers and the mossy-fiberparallel fiber system, heavily influence the growth and differentiation of Purkinje cell dendrites through activity-dependent mechanisms and by chemoattractive and repulsive means.

By late embryogenesis, multiple inferior olivary axons make numerous synaptic contacts on somatic spines of Purkinje cells (Morara et al., 2001). From the end of the first postnatal week, climbing fibers undergo a complex process of regression of multiple innervations (Crepel et al., 1981) and translocation to the developing Purkinje cell dendrites ensues (Scelfo et al., 2003). Initially it was believed that competition for the limited space on the Purkinje cell soma and its dendrites results in the elimination of supernumerary climbing fibers (Hume \& Purves , 1981; Purves \& Hume 1981). What has become clear recently is that glutamatergic signaling via parallel fibers is crucial in the 
regression of multiple climbing fibers. Within a strict time frame (postnatal days 15-16), $N$-methyl-D-aspartate (NMDA) receptor signaling between the parallel fibers and the Purkinje cells is essential for the reduction of climbing fibers (Kakizawa et al., 2000). Furthermore, mice that have a deleted metabotropic glutamate receptor 1 subtype (mGlur1) elicit impaired motor coordination, which has been ascribed to multiple climbing fibers persisting into adulthood (Ichise et al., 2000).

\section{EXPERIMENTAL MODELS OF IMPAIRED CEREBELLAR DEVELOPMENT}

Because of the long developmental profile, the cerebellum is particularly vulnerable to developmental and environmental insults. As the cerebellum is not crucial for life, cerebellar mutants survive into adulthood, making them excellent models to study the contributions of the various elements of the circuitry to overall cerebellar function. Currently, more than 50 naturally occurring mutants have been detailed (see Sotelo, 1990). Only a few of the most extensively studied mutants will be discussed here.

\section{Purkinje cell degeneration mutant}

The Purkinje cell degeneration ( $p c d$ ) mutant is characterized by an almost complete loss of Purkinje cells between PD15 and PD45 (Mullen et al., 1976). This relatively late degeneration of Purkinje cells is preceded by an initially regular formation of the cerebellar circuitry, as well as by the development of the appropriate corticonuclear connectivity (Landis and Mullen, 1978).

Remarkably, the mild motor impairment in pcd mutants belies the gross histological malformation (Mullen et al., 1976). An increase in parvalbumin expression, a calcium binding protein, and the reorganization of intranuclear inhibition in the vestibular nucleus and in the deep cerebellar nuclei apparently compensate to ameliorate the effects of the lack of tonic inhibition normally provided by the GABAergic Purkinje cells (Mullen et al., 1976).

\section{Weaver mouse $(w v)$}

In weaver mice, a single base pair substitution in the gene encoding a G-protein-dependent inwardly rectifying potassium channel protein (GIRK2; Patil et al., 1995) results in an almost complete loss of vermal and paravermal granule cells during the first postnatal weeks. (Rakic \& Sidman, 1973). Secondarily, up to $50 \%$ of Purkinje cells in the vermis die.

Despite the observation that fewer Purkinje cells die in the $w v$ mouse when compared with the $p c d$ mutant, $w v$ mice exhibit severe ataxia with gait instability, poor limb coordination, and tremor at rest, as well as during motion. Gait instability is so severe that adult mutants are unable to stand without swaying (weaving) or to move one step without falling over. This behavioral phenotype results from an inability of this mutant to adjust muscle tone in the trunk and the extremities correctly (Grusser-Cornehls, 1995). The pronounced behavioral deficits of $w v$ mice compared with $p c d$ mice appear to result from a pronounced irregular output of the cerebellum from the disparate regions where Purkinje cells survive. Indeed, ablation of the cerebellum in $w v$ improves motor performance (Grusser-Cornehls et al., 1999).

\section{Leaner mouse tg(la)}

A mutation (leaner $(\operatorname{tg}(l a))$ in the gene encoding the voltage-activated calcium channel alA subunit in mice (Fletcher et al., 1996) results in Purkinje cell, granule cell, and Golgi cell degeneration (Herrup \& Wilczynski, 1982). Granule cell degeneration occurs earliest, at about 3 weeks of age. Between 4 to 6 weeks of age, up to $50 \%$ of Purkinje cells die, reaching a peak of $80 \%$ at about 6 months, and the inhibitory interneurons, the Golgi cells, lose up to $50 \%$ of their total number. Not surprisingly, this mutant exhibits severe motor 
abnormalities, including marked ataxia, slowed motor activity, rigid hypertonia of trunk and limb muscles, but no tremor. In the adult $\operatorname{tg}(l a)$ mouse, the predominant motor symptom is an extreme immobility, due to a rigid hypertonia and a swaying sideways that forces them to 'lean' against the cage walls to avoid toppling over. The pathology of extracerebellar targets is thought to add to the severe behavioral phenotype exhibited by $\operatorname{tg}(l a)$.

The most cogent message emanating from the study of the behavioral phenotypes of various cerebellar mutants is that it appears to be more advantageous to remove the morphologically and functionally impaired cerebellar circuitry completely in order to improve motor abilities. Nevertheless, the transferability of the results from animal to man remains to be proven.

\section{CEREBELLAR PLASTICITY}

The protracted developmental profile of the cerebellum, in relation to other brain structures, makes it highly accessible to ongoing developmental events and amenable to the modification of these events due to the highly plastic nature of this structure (Rossi \& Strata, 1998). Furthermore, the plasticity of the olivocerebellar system offers hope for the treatment of pathologies. Efforts to reverse aberrant cerebellar circuitry during development and in adulthood have focused on transplanting foreign cerebellar tissue in cases of atrophy or degeneration and the use of trophic factors in reorganizing cerebellar circuitry.

\section{Transplantation studies}

In the past, the transplanting cerebellar tissue from normal animals into that of mutant models of cerebellar degeneration was used to assess the viability of repairing cerebellar function. In a morphological study, Sotelo and Alvarado-Mallart, (1986) showed that embryonic Purkinje cells grafted into the cerebellum of $p c d$ mice are able to integrate specifically into the cerebellar circuitry, replacing the missing Purkinje cells. Whilst the embryonic Purkinje cells are able to integrate synaptically in the pcd cerebellum, proper reconstruction of the corticonuclear projection fails to be achieved, placing restrictions on this procedure.

Zhang et al. (1996), however, grafted fetal tissue of normal cerebellum onto the cerebellum of $p c d$ mice, in an attempt at correcting their cellular and motor impairment. The animals showed an improvement of motor behavior in balance rod tests and in the open field, providing evidence for functional integration into the atrophic mouse cerebellum, suggesting that neural transplantation could be a viable means of treating human cerebellar ataxias.

\section{Trophic agents}

The initial phase of neuronal development is governed by intrinsic patterns under the influence of genetic imprints. A large number of genes have been shown to be crucial for the proper formation of cerebellar circuitry (see Wang \& Zoghbi, 2001). Apart from specific genes, other intracellular mediators have also been shown to modulate the development of the cerebellum, in particular, Purkinje cells. Protein kinase $\mathrm{C}$, particularly the gamma isoform, is necessary for the elimination of surplus climbing fiber synapses in adulthood (Kano et al., 1995) and plays a dynamic role in Purkinje cell development as well (Metzger \& Kapfhammer, 2000). Additional endogenous mediators of Purkinje cell development appear to be the neurosteroids, progesterone and estradiol. Purkinje cells actively synthesize these agents from cholesterol during the postnatal period. These neurosteroids promote dendritic growth, spinogenesis, and synaptogenesis via each receptor in the Purkinje cell (Tsutsui et al., 2004).

The secondary phase of development, governed largely by activity dependent mechanisms, and acting via electrical signaling and trophic factors, is crucial for the further development of neurites 
and accounts for the most active period of neural development and circuitry formation (Wong \& Ghosh, 2002). The two main cerebellar afferents, namely the climbing fibers and mossy fibers release aspartate or glutamate, which in turn depolarizes their target neurons, Purkinje cells and granule cells respectively. Co-localized with these neurotransmitters are a diverse group of neuropeptides, such as the calcitonin gene related peptide (CGRP), enkephalin, cholycystokinin, B50, neuropeptide $\mathrm{Y}$, and insulin-growth factor (Kwong et al., 2000).

Neurotrophins. Neurotrophins are a family of molecules that encourage the survival of nervous tissue. Neurotrophic factors are secreted by cells in a neuron's target field. Morrison and Mason (1998) have shown that brain-derived neurotrophic factor (BDNF) or neurotrophin 4 (NT-4) improves but neurotrophin 3 (NT-3) reduces the survival of isolated Purkinje cells, suggesting a complicated interplay of various factors, released by either cerebellar afferents or glia in modulating Purkinje cell differentiation. Tolber and Clark (2003) chronically infused glial-derived neurotrophic factor (GDNF) into shaker mutant rats to rescue the cerebellar Purkinje neurons from adult-onset heterodegeneration. Four weeks of infusion of GDNF rescued Purkinje cells from degeneration. Behaviorally, the animals showed a delayed development of gait ataxia, preserved hip stability, and lower tremor frequencies. These effects, however, were transitory, with the animals resorting to the normal phenotype following the cessation of treatment. Hence, although the results of that study provide promising evidence for the role of GDNF in reversing Purkinje cell degeneration, further efforts are required to prolong its effects.

Insulin-like growth factor I (IGF). IGF is contained in climbing fibers and has been shown to promote Purkinje cell development (Fukudome et al., 2003), to improve cerebellar dysfunction in the leaner mutant (Nahm et al., 2003), and to convey a neuroprotective effect in the injured olivocerebellar pathway (Fernandez et al., 1999). Insulin-like growth factor I also had an additive effect with GDNF in staving off the degeneration in shaker mutants. The neuroplastic ability of IGF is further emphasized by its ability to cause transected olivary axons to re-innervate their appropriate targets, even in adulthood (Sherrard \& Bower, 2003). As with GDNF, however, IGF must be continuously applied to be effective.

Corticotropin releasing factor (CRF). One of the peptides growing in stature as modulators of neuronal development is corticotrophin-releasing factor (CRF) (Vale et al., 1981). The CRF is well established as the major physiological regulator of the hypothalamic-pituitary- adrenal (HPA) axis and serves to coordinate the mammalian endocrine, autonomic, and behavioral responses to stress (Koob \& Heinrichs, 1999). There are, however, extra-hypothalamic sources of CRF, the most prominent being the collection of brainstem nuclei collectively termed the pre-cerebellar nuclei. The pre-cerebellar nuclei express CRF in the axons that form the major afferent systems to the cerebellum, namely the mossy fibers and climbing fibers (Palkovitz et al., 1987). The recently discovered urocortin (Vaughan et al., 1995), which has a more restricted expression profile, is believed to be crucial in sensorimotor integration (Bittencourt et al., 1999).

Both CRF and urocortin couple to two G-protein receptors, namely CRF-R1 and CRF-R2. In vivo, at adult age, the activation of CRF-R1 has been shown to induce locomotor activity (Contarino et al., 2000), whereas the activation of CRF-R2 has an inhibitory effect (Valdez et al., 2002). Crucially, in vitro, CRF is necessary for the induction of long-term depression (LTD) (Miyata et al., 1999), a type of synaptic plasticity and viewed as the cellular basis of motor learning (Ito, 1984). This finding alludes to a direct role for CRF-like peptides in motor coordination and motor learning in adulthood. However, the onset of 
expression of CRF (Bishop \& King, 1999), urocortin, and their receptors (Chang et al., 1993) occurs embryonically, prior to any synapse being formed, suggesting an initial role for CRF-like peptides in the development of the cerebellar circuitry. During the first 3 postnatal weeks, cerebellar neurons undergo considerable structural changes. This period coincides with the maturation of the "CRF system".

Bishop (2002) showed that CRF has a direct excitatory action on Purkinje cells from PD 9 onwards. This effect was most pronounced in lobules IX and X, namely, the region termed the vestibulo-cerebellum, which is mainly concerned with the control of posture and balance. Using cerebellar slice cultures of rats from PD 8, we showed that both CRF and urocortin have a potent effect on Purkinje cell dendritic differentiation (Swinny et al., 2004). Intermittent exposure of the slices to CRF and urocortin (12 hours per day for 10 days in vitro) enhanced dendritic outgrowth and elongation, whereas continuous exposure of the slices to the peptides inhibited growth.

Urocortin was shown to be more potent in inducing dendritic outgrowth, with cells from slices exposed to it intermittently having the highest number of primary dendrites, 5.3 on average. In contrast, CRF was more potent than urocortin in causing dendritic elongation. This finding vindicates earlier suppositions derived from CRF receptor localization data showing that CRF-R2 is mainly expressed in the Purkinje cell soma and CRF-R1 in the Purkinje cell dendritic shaft (Swinny et al., 2002).

Furthermore, in line with previous studies on the binding affinities of CRF and urocortin, the use of receptor antagonists showed that CRF mediates its effects predominantly via CRFR1 and urocortin, apparently via both receptors. Finally, blockade of the PKA and MAPK pathways implicated these secondary messenger pathways in mediating the trophic effects of CRF and urocortin. In light of the in vitro results, studies are needed to see if CRF is capable of reversing the motor deficits in animal models of cerebellar malformation or degeneration.

\section{CONCLUSION}

In conclusion, in this genomic era, the list of mutations that result in cerebellar abnormalities and consequently motor disorders, is steadily being unraveled. With animal models of cerebellar mal-formation having proved invaluable for understanding the function of various cellular elements in the cerebellar circuitry, the next phase of research should aim to remodel or treat such malformations. The use of trophic agents, although currently restricted to in vitro or animal models, could provide a fruitful line of research in treating cerebellar pathologies of a developmental nature.

\section{REFERENCES}

Allen G, Buxton RB, Wong EC, Courchesne E. 1997. Attentional activation of the cerebellum independent of motor involvement. Science 275: 1940-1943.

Altman J, Bayer SA, eds. 1997. Development of the cerebellar system: In relation to its evolution, structure and function. Boca Raton, FL, USA: CRC Press.

Bishop GA. 2002. Development of a corticotropinreleasing factor-mediated effect on the firing rate of Purkinje cells in the postnatal mouse cerebellum. Exp Neurol 178: 165-174.

Bishop GA, King JS. 1999. Corticotropin releasing factor in the embryonic mouse cerebellum. Exp Neurol 160: 489-99.

Bittencourt JC, Vaughan J, Arias C, Rissman RA, Vale WW, Sawchenko PE. 1999. Urocortin expression in rat brain: evidence against a pervasive relationship of urocortin-containing projections with targets bearing type 2 CRF receptors. J Comp Neurol 415: 285-312.

Bloedel JR, Bracha V. 1997. Duality of cerebellar motor and cognitive functions. Int Rev Neurobiol 41: 613-634.

Chang CP, Pearse RV, O'Connell S, Rosenfeld MG. 1993. Identification of a seven transmembrane 
helix receptor for corticotropin-releasing factor and sauvagine in mammalian brain. Neuron 11: 1187-1195.

Contarino A, Dellu F, Koob GF, Smith GW, Lee KF, Vale WW, et al. 2000. Dissociation of locomotor activation and suppression of food intake induced by CRF in CRFR1-deficient mice. Endocrinology. 141: 2698-2702.

Crepel F, Delhaye-Bouchaud N, Dupont JL. 1981. Fate of the multiple innervation of cerebellar Purkinje cells by climbing fibers in immature control, $x$-irradiated and hypothyroid rats. Brain Res 227: 59-71.

Dobbing J, Sands J. 1973. Quantitative growth and development of human brain. Arch Dis Child 48: 757-767.

Doyon J, Song AW, Karni A, Lalonde F, Adams MM, Ungerleider LG. 2002. Experience dependent changes in cerebellar contributions to motor sequence learning. Proc Natl Acad Sci USA 99: 1017-1022.

Fernandez AM, Gonzalez de la Vega AG, Planas B, Torres-Aleman I. 1999. Neuroprotective actions of peripherally administered insulin-like growth factor $\mathrm{I}$ in the injured olivo-cerebellar pathway. Eur J NeuroSci 11: 2019-2030.

Fletcher CF, Lutz CM, O'Sullivan TN, Shaughnessy JD Jr., Hawkes R, Frankel WN, et al. 1996. Absence epilepsy in tottering mutant mice is associated with calcium channel defects. Cell 87: 607-617.

Fukudome Y, Tabata T, Miyoshi T, Haruki S, Araishi K, Sawada S, et al. 2003. Insulin-like growth factor-I as a promoting factor for cerebellar Purkinje cell development. Eur J NeuroSci 17: 2006-2016.

Geisler HC, Westerga J, Gramsbergen A. 1996. The function of the long back muscles during postural development in the rat. Behav Brain Res 80: 211 215.

Goldowitz D, Hamre K. 1998. The cells and molecules that make a cerebellum. Trends NeuroSci 21: 375382.

Grusser-Cornehls U. 1995. Response of flocculus and vestibular nuclei neurons in weaver mutant mice (B6CBA wv:wv) to combined head and body rotation. Exp Brain Res 105: 26-33.

Grusser-Cornehls U, Grusser C, Baurle J. 1999. Vermectomy enhances parvalbumin expression and improves motor performance in Weaver mutant mice: an animal model for cerebellar ataxia. Neuroscience 91: 315-326.
Herrup K, Wilczynski SL. 1982. Cerebellar cell degeneration in the leaner mutant mouse Neuroscience 7: 2185-2196.

Hume RI, Purves D. 1981. Geometry of neonatal neurones and the regulation of synapse elimination. Nature 293: 469-471.

Ichise $T$, Kano $M$, Hashimoto $K$. Yanagihara $D$, Nakao K, Shigemoto R, et al. 2000. mGluR1 in cerebellar Purkinje cells essential for long-term depression, synapse elimination, and motor coordination. Science 2000. 288: 1832-1835.

Ito M. 1984 The Cerebellum and Neural Control. New York, NY, USA: Raven Press.

Kakizawa S, Yamasaki M, Watanabe M, Kano M. 2000. Critical period for activity-dependent synapse elimination in developing cerebellum. J NeuroSci 20: 4954-4961.

Kano M, Hashimoto K, Chen C, Abeliovich A, Aiba A, Kurihara $\mathrm{H}$, et al. 1995. Impaired synapse elimination during cerebellar development in PKC gamma mutant mice. Cell 83: 1223-1231.

Koob GF, Heinrichs SC. 1999. A role for corticotropin releasing factor and urocortin in behavioral responses to stressors. Brain Res 848: 141-152.

Kwong WH, Chan WY, Lee KK, Fan M, Yew DT. 2000. Neurotransmitters, neuropeptides and calcium binding proteins in developing human cerebellum: a review. Histochem J 32: 521-534.

Landis SC, Mullen RJ. 1978. The development and degeneration of Purkinje cells in ped mutant mice. J Comp Neurol 177: 125-144.

Metzger F, Kapfhammer JP. 2000. Protein kinase C activity modulates dendritic differentiation of rat Purkinje cells in cerebellar slice cultures Eur $\mathbf{J}$ NeuroSci 12: 1993-2005.

Miyata M, Okada D, Hashimoto K, Kano M, Ito $M$. 1999. Corticotropin-releasing factor plays a permissive role in cerebellar long-term depression. Neuron 22: 763-775.

Morara S, van der Want JJ, de Weerd H, Provini L, Rosina A. 2001. Ultrastructural analysis of climbing fiber-Purkinje cell synaptogenesis in the rat cerebellum. Neuroscience 108: 655-671.

Morrison ME, Mason CA. Morrison ME, Mason CA. 1998. Granule neuron regulation of Purkinje cell development: striking a balance between neurotrophin and glutamate signaling. J NeuroSci 18 : 3563-3573.

Mullen RJ, Eicher EM, Sidman RL. 1976. Purkinje cell degeneration, a new neurological mutation in the mouse. Proc Natl Acad Sci 73: 208-212. 
Nahm SS, Frank TC, Browning MD, Sepulvado JM, Hiney JK, Abbott LC. 2003. Insulin-like growth factor-I improves cerebellar dysfunction but does not prevent cerebellar neurodegeneration in the calcium channel mutant mouse, leaner. Neurobiol Dis 14: 157-165.

Palkovits M, Leranth C, Gorcs T, Young WS. 1987. Corticotropin-releasing factor in the olivocerebellar tract of rats: demonstration by light- and electron-microscopic immunohistochemistry and in situ hybridization histochemistry. Proc Natl Acad Sci 84: 3911-3915.

Patil N, Cox DR, Bhat D, Faham M, Myers RM, Peterson AS. 1995. A potassium channel mutation in weaver mice implicates membrane excitability in granule cell differentiation. Nat Genet 11:126129.

Purves D Hume RI. The relation of postsynaptic geometry to the number of presynaptic axons that innervate autonomic ganglion cells. J Neurosci 1981.1: 441-452.

Rakic P, Sidman RL. 1973. Sequence of developmental abnormalities leading to granule cell deficit in cerebellar cortex of weaver mutant mice. J Comp Neurol 152: 103-132.

Roffler-Tarlov S, Beart PM, O'Gorman S, Sidman RL. 1979. Neurochemical and morphological conesquences of axon terminal degeneration in cerebellar deep nuclei of mice with inherited Purkinje cell degeneration. Brain Res 168: 75-95.

Scelfo B, Strata P, Knopfel T. 2003. Sodium imaging of climbing fiber innervation fields in developing mouse Purkinje cells. J Neurophysiol 89: 25552563.

Sherrard RM, Bower AJ. 2003. IGF-1 induces neonatal climbing-fiber plasticity in the mature rat cerebellum. Neuroreport 14: 1713-1716.

Sotelo C, Alvarado-Mallart RM. 1986. Growth and differentiation of cerebellar suspensions transplanted into the adult cerebellum of mice with heredodegenerative ataxia. Proc Natl Acad Sci 83: 1135-1139.

Sotelo C. 1990 . Cerebellar synaptogenesis: what we can learn from mutant mice. J Exp Biol 153: 225-249.

Strata P, Rossi F. 1998. Plasticity of the olivo-cerebellar pathway. Trends NeuroSci $21: 407-413$.
Swinny JD, Kalicharan D, Blaauw EH, Ijkema-Paassen J, Shi F, Gramsbergen A, et al. 2003. Corticotropin-releasing factor receptor types 1 and 2 are differentially expressed in pre- and post-synaptic elements in the post-natal developing rat cerebellum. Eur J NeuroSci 18: 549-562.

Swinny JD, Metzger F, IJkema-Paassen J, Gounko NV, Gramsbergen A, van der Want JJ. 2004 Corticotropin-releasing factor and urocortin differentially modulate rat Purkinje cell dendritic outgrowth and differentiation in vitro. Eur $J$ NeuroSci 19: 1749-1758.

Tsutsui K, Sakamoto H, Shikimi H, Ukena K. 2004. Organizing actions of neurosteroids in the Purkinje Neuron Neurosci Res 49: 273-279.

Tolbert DL, Clark BR. 2003. GDNF and IGF-I trophic factors delay hereditary Purkinje cell degeneration and the progression of gait ataxia. Exp Neurol 183: 205-219

Valdez GR, Inoue $\mathrm{K}$, Koob GF, Rivier J, Vale W, Zorrilla EP. 2002. Human urocortin II: mild locomotor suppressive and delayed anxiolytic-like effects of a novel corticotropin-releasing factor related peptide. Brain Res 943: 142-150.

Vale W, Spiess J, Rivier C, Rivier J. 1981. Characterization of a 41-residue ovine hypothalamic peptide that stimulates secretion of corticotropin and betaendorphin. Science. 213: 1394-1397.

Vaughan J, Donaldson C, Bittencourt J, Perrin MH, Lewis K, Sutton S, et al. 1995. Urocortin, a mammalian neuropeptide related to fish urotensin $I$ and to corticotropin-releasing factor. Nature 378: 233-234.

Westerga J, Gramsbergen A. 1994. Development of the EMG of the soleus muscle in the rat. Brain Res Dev Brain Res 80: 233-243.

Wang VY, Zoghbi HY. 2001. Genetic regulation of cerebellar development. Nat Rev NeuroSci 2: 484-491.

Wong RO, Ghosh A. 2002. Activity-dependent regulation of dendritic growth and patterning. Nat Rev NeuroSci 3: 803-812.

Zhang W, Lee WH, Triarhou LC. 1996. Grafted cerebellar cells in a mouse model of hereditary ataxia express IGF-I system genes and partially restore behavioral function. Nat Med. 2: 65-71. 

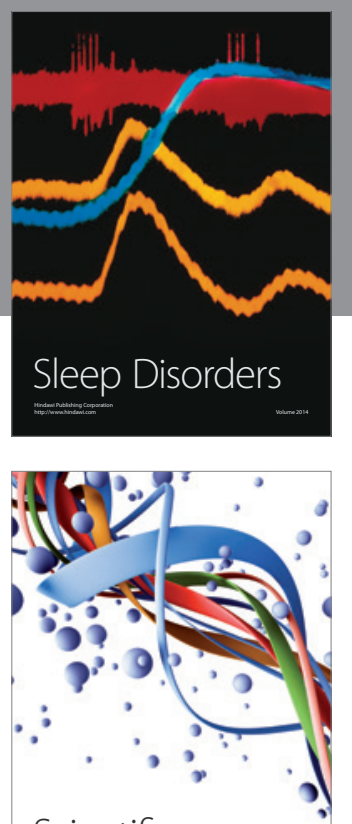

Scientifica
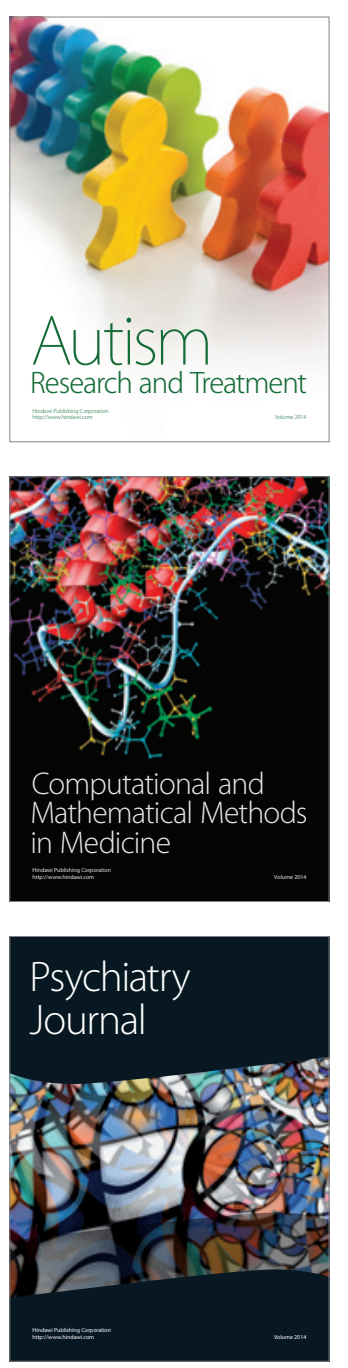
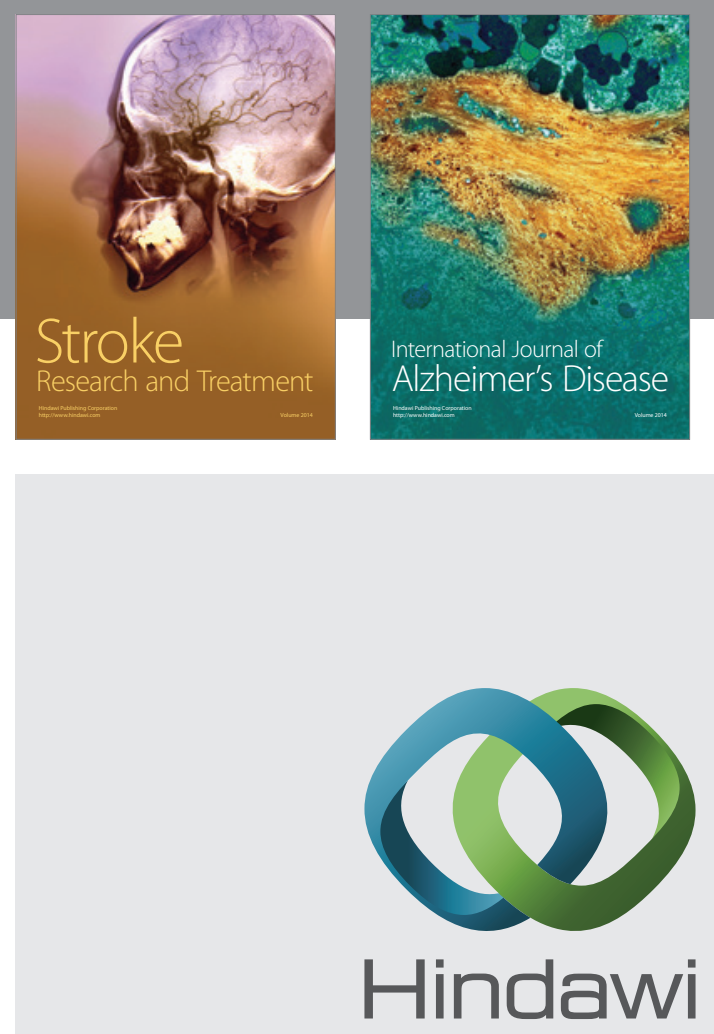

Submit your manuscripts at

http://www.hindawi.com
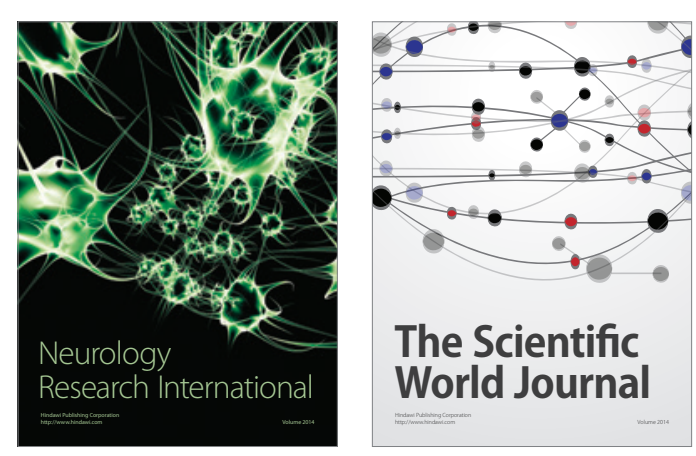

The Scientific World Journal

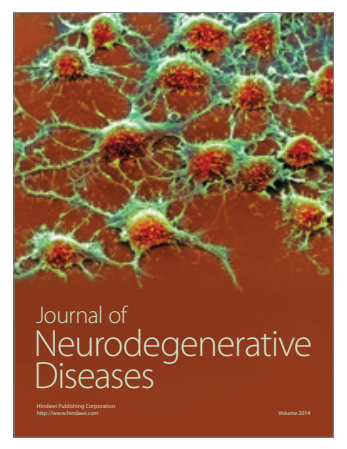

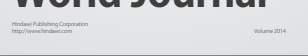

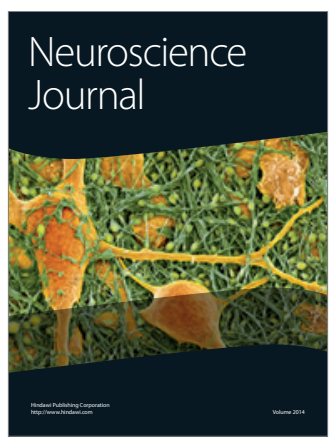

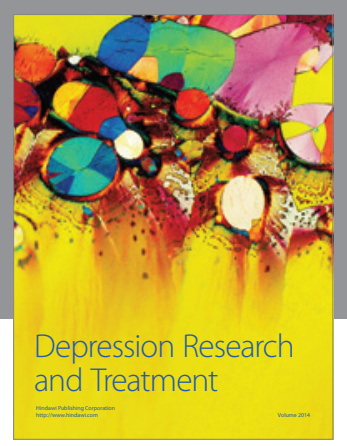
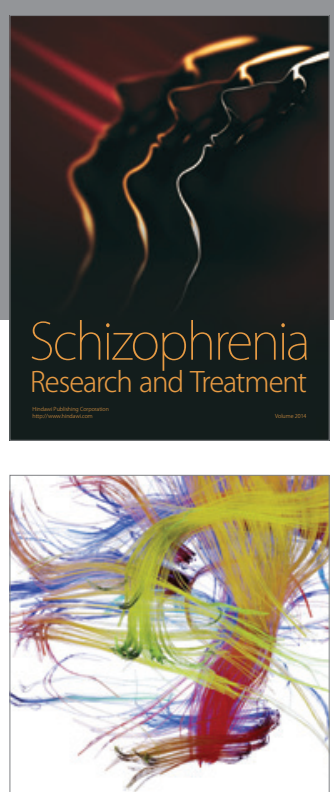

Brain Science

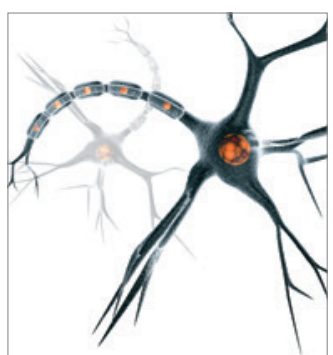

Neural Plasticity
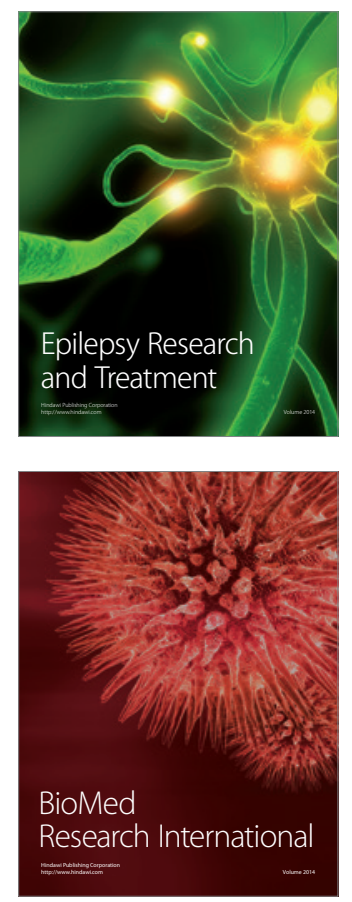

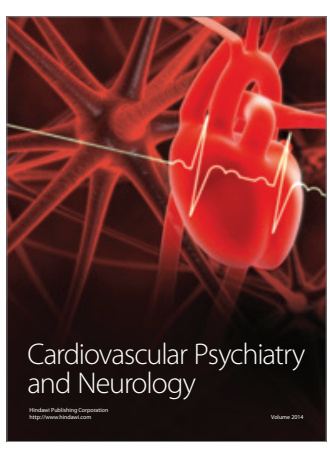

Parkinson's

Disease
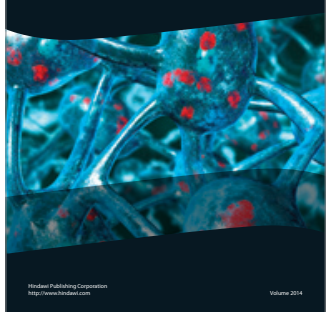